\title{
Humerus midshaft histology in a modern and fossil wombat
}

Meg M. Walker ${ }^{1}$, Julien Louys ${ }^{2}$, Andy I. R. Herries ${ }^{3,4}$, Gilbert J. Price ${ }^{5}$, Justyna J. Miszkiewicz ${ }^{1}$

${ }^{1}$ School of Archaeology and Anthropology, Australian National University, Canberra 0200, Australian Capital Territory, Australia

${ }^{2}$ Australian Research Centre for Human Evolution, Griffith University, Brisbane 4111, Queensland, Australia

${ }^{3}$ Palaeoscience, Department of Archaeology and History, La Trobe University, Melbourne Campus, Bundoora, 3086, Victoria, Australia

${ }^{4}$ Centre for Anthropological Palaeo-Research Institute, University of Johannesburg, Bunting Road Campus, Auckland Park, Gauteng, South Africa

${ }^{5}$ School of Earth and Environmental Sciences, The University of Queensland, Brisbane 4072, Queensland, Australia

Running title: Wombat bone histology

\section{Corresponding authors:}

Meg M. Walker walker.meg1@gmail.com

School of Archaeology and Anthropology

The Australian National University

44 Linnaeus Way

2601 Canberra, ACT, Australia

Office: +61261259295 


\begin{abstract}
The common wombat (Vombatus ursinus) is equipped with a set of physiological and morphological adaptations suited to a fossorial lifestyle. These allow wombats to engage in efficient scratch-digging and maintaining a low basal metabolic rate - all the while spending prolonged periods of time underground. While bone microstructure has been described for several subterranean animals, including mole-rats and the aardvark, wombat bone histology has received very little attention to date. Here, we present preliminary insights into bone histology in modern adult V. ursinus (Mt Fairy, NSW) and Pleistocene fossil Vombatus sp. (Bakers Swamp, NSW) midshaft humeri. The modern sample was of an almost pristine preservation, allowing us to identify a combination of varying bone tissue types (woven, parallel-fibered, lamellar). The sample showed complex vascularity with a mixture of primary and secondary osteons, and simple longitudinal and radial vessels. We also observed evidence for widespread Haversian remodelling (i.e. localised replacement or pre-existing bone), and restricted areas of coarse compact cancellous bone contained within the inner cortex of the diaphysis. The fossil histology was poorly preserved, but likely showed bone matrix organisation (e.g. medullary trabeculae positioning, high vascularity) similar to the modern specimen. We use these preliminary data to discuss hypotheses for wombat forelimb biomechanical and physiological microscopic adaptation to a burrow environment. We encourage future systematic examination of intra-skeletal bone microstructure in wombat populations to better inform their unique ecological adaptations and assist in reconstructing wombat behaviour in palaeontological contexts.
\end{abstract}

Keywords: microstructure, biomechanics, forelimb, marsupials, Pleistocene 


\section{Introduction}

Histology has long been successfully applied to both palaeontological and modern tetrapod samples, revealing bone microscopic features linked to behaviour, life history, biology, physiology, skeletal development, and phylogenetics (e.g. de Ricqlès 2011; Marín-Moratalla and Jordana 2013; Padian and Lamm, 2013; Straehl et al. 2013; Miszkiewicz et al. 2020). However, bone histology in Australian marsupials has received very little attention. To the best of our knowledge, only three studies have considered modern Vombatus ursinus hard tissue histology (Werning 2013; Slon et al. 2014; Felder et al. 2017), and none in a palaeontological context. One of these studies investigated wombat hyperostotic bone disease (Slon et al. 2014), and another used geometric properties of a single wombat bone isolated unit (secondary osteon) to examine scaling relationships between body size and histology as part of multi-species mammalian comparisons (Felder et al. 2017). Werning (2013) included V. ursinus bone histology data, Diprotodon optatum, and other Diprotodontia as part of broader analyses of the evolution of growth rates and metabolism in amniotes.

Wombats are excellent candidates for bone histological analyses because of their suite of specialised morphological (e.g. powerful forelimbs and efficient scratch-digging) and physiological (e.g. thermoregulation and low basal metabolic rate) adaptations needed to live in a subterranean environment. Fossil wombat lifestyles, particularly concerning questions that relate to burrowing in deep time, remain unresolved (Woolnough and Steele 2001). Vombatus ursinus is the only extant species of the genus Vombatus, of which four are known in the fossil record: V. ursinus, V. parvus, V. hacketti, and V. mitchellii (Murray 1998, Louys 2015). The earliest known member of the Vombatidae, Rhizophascolonus crowcrofti, is dated to the Early Miocene (Brewer et al. 2018). All species within this family show some degree of hypsodonty and fossorial scratch-digging (Murray 1998), combined with a large body mass and a herbivorous diet (Johnson 1998). The origins of these adaptive traits and their relation to burrowing environments is debated (Murray 1998; Johnson, 1998).

Modern wombats have a range of complementary biological energy-saving and energymaximising traits (Barboza 1993). They have heavy and highly adapted digging humeri, a compact body, and strong claws which support burrowing behaviour and reduce energy expenditure (Johnson 1998). Fossorial mammals are typically small or consume high energy yield forage to satisfy large energy expenditure related to burrowing, yet wombats can achieve large body size (up to $35 \mathrm{~kg}$ ) whilst foraging on low quality fodder (McIlroy, 1973). High, but 
short term-energy expenditure is required to build a burrow whilst low long-term energy is needed to maintain one (Vleck 1979). To that end, wombats show extremely low basal metabolic rates (BMR). Their adaptive masticatory functions reduce food into fine particles which decreases the amount of energy needed for digestive processes (Barboza 1993). Their colonic digestive system helps with food fermentation increasing food capacity by $30 \%$ over the estimated value derived from body mass (Barboza and Hume 1992a, 1992b). This is supported by a long retention period which maximises the digestibility of low-quality forage (Barboza 1993). Concentration of plasma in thyroid hormones, indicative of metabolism and nitrogen requirements, is known to be some of the lowest when compared to other mammals (Barboza et al. 1993).

Wombats can regulate constant temperature and humidity within their burrows through their adaptive traits (Wells, 1978). The burrow reduces the amount of energy required in thermoregulation that complements other energy-saving biological adaptations (Wells 1973; Contreras and McNab 1990). Reduced thermoregulation is hypothesised to result in the aforementioned lower metabolic rates (Contreras and McNab 1990). Consequently, as wombats are sensitive to hypothermia (Murray 1998), they will avoid venturing outside until outside conditions match the burrow temperature and humidity (Wells 1978). Therefore, wombats shift their emergence from the burrow throughout the year based on seasonal variation. Doing so saves up to $57 \%$ of respiratory water loss (Wells 1978). Constantly humid temperatures, accompanying a low metabolic rate and behavioural variation, also reduce water turnover by breathing in close to saturated air. The southern hairy nose wombat (Lasiorhinus latifrons) has been shown to have a water turnover rate of less than $22 \mathrm{ml} / \mathrm{kg}$ per day (Wells 1973). The burrow is also a hypoxic and hypercapnic environment (Boggs et al. 1984). To deal with a saturated $\mathrm{CO}_{2}$ environment, wombats have variable respiratory responses (Withers 1972).

The morphology of skeletal elements at both the macroscopic and microscopic level varies across species due to phylogenetic, physiological, metabolic, mechanical, and environmental stimuli (Cubo et al. 2008; Huttenlocker et al. 2013). The unique adaptive biological constraints of the burrow environment, and fossorial activity, should therefore be reflected in wombat bone histology. Variations in resting metabolic rate (RMR) can be linked to growth rates (dioxygen consumption and mass) (Padian et al. 2001; Cubo et al. 2008), and body mass is linked to bone metabolism (Bromage et al. 2009; Hogg et al. 2017; Miszkiewicz et al. 2020). Processes of 
bone growth (modelling) and renewal (remodelling) are reflected in the rate of deposition of bone tissue, the organisation of the bone matrix via the orientation of collagen fibrils, as well as bone vascularity, all seen histologically (de Ricqlès 2011). A stratigraphic-like record of varying growth rates and responses to biomechanical loading are captured microstructurally (Francillon-Vieillot et al. 1990; de Ricqlès 2011; Huttenlocker et al., 2013). Here, we provide preliminary insights into modern wombat midshaft humerus histological appearance with remarks on histological applications to fossil wombat behaviour.

\section{Materials and methods}

\section{Humerus specimens}

This study examined one right and one left adult wombat humerus (Fig. 1). The specimens were from a fossil Vombatus sp., and a modern V. ursinus. The modern (MW) specimen was a surface find recovered as part of a palaeontological survey of Mt Fairy, Lake George, New South Wales. The fossil specimen (FW) was collected from A'Beckett's Cave at Bakers Swamp, New South Wales, around $20 \mathrm{~km}$ south of the Wellington Caves fossil sites. The FW fossil was recovered from a dense fossil accumulation located at the bottom of the cave where fossil bearing sediments are overlain by speleothem. Two speleothems were dated by uraniumseries, the oldest of which is $93.7 \pm 0.3 \mathrm{ka}$ and represents the minimum age for the fossil deposits (Supplementary Table 1). The sediments underlying this have a normal magnetic polarity, suggesting deposition during the Brunhes Chron within the last $780 \mathrm{ka}$ (Singer, 2014). The fossil sample is therefore Middle Pleistocene or very early Upper Pleistocene in age sometime between $\sim 780$ and $\sim 94 \mathrm{ka}$. Both humeri are from the vertebrate palaeontology collection at the Australian Research Centre for Human Evolution at Griffith University, Brisbane. Three (one modern and two fossil bone) thin sections produced as part of this study were accessioned into the Hard Tissue Histology collection of the School of Archaeology and Anthropology at the Australian National University (accession IDs are ANU_SOAA_WHM for the modern specimen, and ANU_SOAA_WHF1 and WHF2 for the fossil specimen).

\section{Osteological analysis}

A complete osteological analysis of the humeri was conducted to collect morphometric data prior to invasive sampling for histology. A pictorial record of both samples was established by photographing all the all sides of the specimens using a Cannon EOS 5D Macro $100 \mathrm{~mm}$ lens, and a Nikon Coolpix AW 130 camera. Following von den Driesch's (1976) guide, discrete 
dimensions were recorded using digital callipers, a sliding measuring board, and a flexible tape measure. Although we aimed to take as many measurements as possible, taphonomic damage to the FW resulted in the loss of the proximal portion and both distal epicondyles (Fig. 1). In contrast, the MW humerus was complete. The measurements (von den Driesch 1978) taken in mm were: GL (greatest length), Bp (greatest length of the proximal end), Dp (depth of the proximal end), SD (smallest breadth of diaphysis), Bd (greatest breadth of the distal end), BT (greatest breadth of the trochlea), and the minimum diaphyseal circumference.

\section{Histological preparation}

Histological sections were prepared using midshaft bone as that is where periosteal muscle attachment sites are found (e.g. for the deltoid, deltopectoral aponeurosis, pectoralis major, brachialis muscle, teres major, latissimus dorsi tendons) (Murray 1998). Histological preparation followed standard methods for dry and undecalcified bone samples (e.g. Padian and Lamm 2013; Miszkiewicz et al. 2019; 2020). The samples were taken from the same location at the midshaft diaphyseal humerus across the deltopectoral crest (DPC). Using an Arlec 12V Supertool, and a Dremel cut off wheel (\#409) and Dremel Reinforced wheel, two transverse parallel cuts were made so that the extracted section was approximately $5 \mathrm{~mm}$ in width $(\mathrm{MW}=5.23-6.60 \mathrm{~mm}, \mathrm{FW}=4.90-5.80 \mathrm{~mm})$ to extract full cross-sections. Samples were embedded using Buehler SamplKups ${ }^{\circledR}$ and Buehler EpoxiCure ${ }^{\circledR}$ Epoxy Resin solution. Once hardened, the samples were removed and mounted onto a Kemet ${ }^{\circledR}$ Metkon MICRACUT 151 precision cutter with a Diamond cutting Disc, 150mm diameter, set at $204 \mathrm{rpm}$. Samples were reduced by trimming excess plastic material on the medial, caudal, and cranial side on the MW, and the caudal side of the FW in a sagittal plane. The samples were then sectioned in the transverse plane from the caudal to cranial border. Samples were mounted onto a clean glass microscope slide using instant clear long lasting, solvent free and water-resistant adhesive Araldite $\AA$, and then ground down both manually and using an automatic Buehler Eco-Met 300 Grinder-Polisher. The final sections measured $\sim 150 \mu \mathrm{m}$. The samples were polished on a wet Beuhler Polishing cloth with Buehler MicroPolish II $0.3 \mu \mathrm{m}$ powder to remove scratches. Samples were washed, dried, and placed in an ultrasonic bath for two minutes to remove microdebris. Following this, water was removed from the samples through dehydration in a series of alcohol baths. Finally, thin sections were cleared in Xylene and covered with a cover slip. 


\section{Microscope imaging}

The thin sections were studied under objective magnifications of $x 2, x 4, x 10, x 20, x 40$, and $\mathrm{x} 60$ using a series of microscopes. Initial imaging was undertaken using an Olympus CX31 microscope with an Olympus CS30 3MP colour camera and Olympus Steam V1.9.1 imaging software; and an AmScope microscope with an AmScope MU130 colour camera, and AmScope 3.2 imaging software. Advanced imaging, including the creation of automatically stitched histology overview images (Fig. 2), was done using an Olympus BX53 with an Olympus DP74 camera for transmitted and linearly polarised light; and an Olympus BX53 polarising microscope with a DP74 camera equipped with a lambda plate (Olympus U-TP530); both operated using the Olympus CellSens ${ }^{\circledR}$ software. Higher resolution images are available as supplementary files (Supplementary Fig. 1-3). Quantitative analyses of the images were completed using the open source program Image $\mathrm{J}($.

\section{Bone tissue analysis}

The samples were first assessed for the extent of taphonomic alteration following the Oxford Histological Index (OHI) (Hedges et al. 1995). Histomorphological parameters (bone tissue descriptions) and histomorphometric data (quantifying bone histology) collected were then defined based on preservation.

\section{Histomorphological parameters}

Bone tissue analysis follows the terminology described by Francillon-Vieillot et al. (1990). The organisation of bone matrix (i.e. classified as woven-fibered, parallel-fibred, lamellar bone), and vascularisation patterns (vessel morphology and orientation) are described. Woven bone has disorganised collagen fibrils and appears isotropic under polarised light. Parallelfibered bone (PFB) contains parallel, closely packed collagen fibrils aligned in one orientation, which are anisotropic and consistently dark or light when polarised. Lamellar bone consists of tightly packed lamellae that show up as alternating bright and dark bands under polarised light (Huttenlocker et al. 2013; Francillon-Vieillot et al. 1990). The presence of varying tissue types in one thin section can indicate different stages of growth. For example, woven-fibered bone is deposited rapidly, whereas lamellar bone is deposited slowly (Amprino 1947; de Margerie et al. 2004; Shapiro and Wu 2019). Vascularisation of bone tissue is essential in characterising bone growth and maintenance. Francillon-Vieillot et al. (1990) outlined four vessel categories: non-vascular bone, primary canals of one orientation (longitudinal, circular, radial, or oblique), 
primary canals of more than one orientation, and secondary canals. These further take form of simple primary vessels, primary osteons, and secondary osteons (Huttenlocker et al. 2013). Presence of secondary osteons indicates Haversian remodelling, which is evidence for deposition of secondary bone tissue that can be associated with increasing age and response to biomechanical load (Miszkiewicz et al. 2019).

\section{Histomorphometric data}

The Image J ${ }^{\circledR}$ “polygon” selection tool was used to measure section area by tracing around the outer periosteal boarder of each specimen, and then the most inner trabecular bone surfaces in the endosteal region of bone, as well as selecting regions obscured taphonomically. The measurable area was then calculated by subtracting the trabecular bone, taphonomic alterations, and empty spaces of the image from the total area measurement. A total vascularisation estimate was calculated by counting all visible simple primary vascular canals, and primary and secondary osteons. Two observers (MMW and JJM) confirmed the identification of canals. The counts were collected using the ImageJ® "multipoint" tool. The total number was then divided by the total measurable area, giving a density estimate of total bone vascularity.

\section{Results}

The gross morphology of the MW was overall more robust (larger and more compact), but smoother and rounder than the FW which was gracile (smaller and more slender) and showed a more angular diaphysis (Fig. 1). Although the FW was incomplete, the MW was larger where comparable measurements could be made. These included the SD (smallest breadth of diaphysis) and BT (greatest breadth of the trochlea) (Table 1).

\section{Modern wombat humerus histology}

The MW presented extremely minor levels of bioerosion with over $95 \%$ of the microstructure and collagen preserved, visible, and easily discernible (OHI =5) (Hedges et al., 1995) (Fig. 2, 3). The cross-section shape of this specimen is gracile and tear-shaped due to its elongated portion for the DPC and the rounded diaphysis on the caudal aspect. The length from the DPC to the medial diaphysis is approximately $25.40 \mathrm{~mm}$. Trabeculae are distinctly present throughout the centre of the DPC region, surrounded by vascular, woven and parallel-fibered bone tissue along the sub-periosteal envelope. Oblique, longitudinal primary osteons, and 
simple primary vascular canals are dispersed randomly throughout the lateral, caudal, and cranial surfaces of the DPC. Anastomosing reticular vascularisation is observed on the border of the cancellous and compact bone where the DPC meets the cranial diaphysis. Surrounding the medullary space, on the caudal-medial endosteal border, is an inner circumferential layer (seen distinctly in blue in Fig. 2c) which is not prominently seen elsewhere around the medulla. Further into the cortex, and surrounding the caudal-lateral and cranial medullary space, is secondary endosteal spongiosa. On the caudal endosteal margin the spongiosa is birefringent and constructed with lamellae. Alternatively, on the cranial endosteal border remodelling of spongiosa is prevalent with disorganised collagen fibrils. In the medial-caudal region restricted areas of coarse compact cancellous bone (CCCB) are seen, owing to a distinct mesh-like appearance (Fig. 2c, 3c).

Throughout the cortex of the diaphysis, parallel-fibered, woven, and Haversian bone with clusters of secondary osteons are observed. Though remodelling activity varies throughout the bone cortex, dense remodelling occurs across the breadth of the medial-cranial cortical region, and the inner medial cortical tissue, but becomes less apparent on the lateral-caudal subperiosteal aspect (Fig. 2, 3a-b, 3d). Here, secondary osteons are disorganised with prominent asymmetric, longitudinal and oblique reticular vascularisation. Some radial and circular simple primary vessels are present but in lower frequencies (Fig. 3). From the mid to outer cortex, in regions unobscured by remodelling, parallel-fibered tissue dominates. Moving towards the periosteum, parallel-fibered bone becomes more prominent where the same previously described band of vessels are seen (Fig. 3d). The outer cortex of the bone is comprised of lamellar bone with minor occurrences of radial and longitudinal simple primary vessels, and isolated secondary osteons (Fig. 3a, 3d). No clear lines of arrested growth (LAGs) or annuli circumnavigate the entire diaphysis. However, bone growth marks are observed in the periosteal envelope (Fig. 3a). For the entire sample, excluding the spongiosa, vascularity was estimated at 11.47 vessels $/ \mathrm{mm}^{2}$. Osteocyte lacunae are seen in high numbers and in close proximity to each other (Fig. $4 b, 4 d)$.

\section{Fossil wombat humerus bone histology}

The FW has prominent but restricted levels of bioerosion along the caudal periosteal border and dispersed throughout the cortex of the DPC (Fig. 5). This means that its bone microorganisation is difficult to describe, though circular vessels were still visible and regions of interest with defined osteocyte lacunae were identified (Fig. 5a, 5b). The cortex showed regions 
of dissolution within the bone matrix and erosion, which meant it was designated an OHI score of 3 (Hedges et al. 1995). We also observed a lack of birefringence in the majority of the FW sample potentially due to collagen loss (Kendall et al. 2018). Therefore, our descriptions of bone are limited.

The FW cross-section shows a triangular diaphysis, with a relatively thick cortical bone along the caudal diaphysis and surrounding the DPC portion of the bone (Fig. 5). Similar to the modern specimen, spongiosa is dispersed well into and within the centre of the DPC region. Trabeculae are located around the medullary cavity, and they appear to occupy larger areas of the cortical band when compared to the modern specimen. From the medial diaphysis, the lateral DPC the midshaft measured $20.98 \mathrm{~mm}$. A conservative estimate of vascular density was established at 11.09 vessels $/ \mathrm{mm}^{2}$. There were isolated regions of interest that showed widely dispersed osteocyte lacunae with increased distances between the neighbouring cell cavities (Fig. 4a, 4c). A thin periosteal border is possible (Fig. 5b).

\section{Discussion}

Comparing the fossil and modern specimens, it is evident that the cortical width surrounding the DPC is greater in the fossil specimen. However, its overall gracileness and triangular shape differ significantly from the larger, more robust yet more round modern specimen. As the wombat humerus is highly adapted to scratch-digging behaviour, a prominent DPC and teres major tuberosity supporting the specialised scapular humeral muscles needed for digging explain the shape differences (Murray 1998). Variations of these features are seen across different species within the genera but are also seen within the same species (Murray 1998). It is possible that this may be a result of phylogenetic and environmental factors such as varying densities of soil substrates, topography, digging posture, and locomotor requirements (Murray 1998; Scott and Richardson 1987). As our specimens are identified to the same genus, but are from different locations and time periods, this could be a function of the environment or burrowing in different soil substrate. Alternatively, these humerus midshaft morphological disparities could represent different species. We do not know the age or sex of the two specimens, but we can hypothesise bone growth links to wombat behaviour and physiology.

\section{Adaptation to scratch-digging}

Digging marsupials are equipped with short and robust forelimbs that facilitate efficient, yet stable movement (Warburton et al. 2014). This means that the internal structure of a wombat 
humerus should be adapted to biomechanical constraints allowing it to function without compromising bone tissue quality. Based on the bone histology sample in our modern specimen, it is apparent that the humeral bone tissue is highly vascularised and predominantly comprised of longitudinal and reticular simple primary vascular canals, and primary and secondary osteons. High vascularisation facilitates blood supply for bone maintenance (Miszkiewicz et al. 2019), and bone remodelling response to load is well-established (Lee et al. 2002). In our modern sample, dense remodelling concentrated across the cortex of the diaphysis is evidence for production of secondary lamellar bone and may occur in some of these regions in response to mechanical load. This would explain the occurrence of secondary osteons very close to the periosteal border where new bone tends to be deposited in cases of increased and repetitive strain (Robling et al. 2006). However, previous research examining the fossorial South African aardvark (Orycteropus afer) reported higher remodelling in the lower arm of the forelimb than the humerus (Legendre and Botha-Brink 2018). Therefore, future research should examine bone histology in all wombat limb bones to better understand and explain any patterns relating to biomechanical bone remodelling intra-skeletally. Generally, the observation of secondary osteons that indicates Haversian remodelling of the wombat humerus cortical bone agrees with reports for other fossorial animals such as the Cape dune molerat (Bathyergus suillus) (Montoya-Sanhueza and Chinsamy 2017), as well as observations made by Werning (2013: 338; Fig 3.15).

\section{Ecological considerations of fossorial lifestyle}

Further related to wombat humerus biomechanical constraints are ecological aspects of fossorial lifestyle. Early in ontogeny, a growing wombat must already engage in digging behaviour, all the while living within an underground niche. Indeed, multiple factors of fossorial living define and affect a wombat including its body mass, resource availability, reduced oxygen supply within a burrow, burrow size (McNab 1979), and even social systems (Noonan et al. 2015). McNab (1979) showed that burrow living is strongly associated with body size, temperature regulation, and reduced BMR. Recent bone histology research on subterranean mammals has considered a suite of skeletal microstructural characteristics describing bone tissue in mammals living underground (Montoya-Sanhueza and Chinsamy 2017; Legendre and Botha-Brink 2018). For example, increased ontogenetic periosteal and endosteal cortical thickening, and presence of $\mathrm{CCCB}$, were found in the Cape dune molerat ( $B$. suillus) (Montoya-Sanhueza and Chinsamy 2017). Legendre and Botha-Brink (2018) also 
discussed the occurrence of significant amounts of CCCB in the South African aardvark $(O$. afer) as a physiological and biomechanical compromise possibly suited to fossoriality. They noted very little secondary remodelling of CCCB in their samples, though this type of bone is usually remodelled early in other animals. Compared to cortical bone, less energy is required to maintain $\mathrm{CCCB}$ which means a reduced, energy-saving, metabolic input into bone homeostasis (Warshaw et al. 2017). Whether wombats conform to these bone histology descriptions reported for other fossorial animals remains unconfirmed until data are available for the entire skeleton and throughout ontogeny. At this stage, we show small amounts of CCCB in our modern sample, though Montoya-Sanhueza and Chinsamy (2017) emphasise a lack of direct relationship of this type of bone to fossoriality.

Despite our limited sample size, we can hypothesise some links of bone histology to aspects of wombat life history as ontogenetic growth rates can be reconstructed from microstructure (Lee et al. 2013). Common wombats are seasonal breeders that vary in reproduction based on latitude and altitude. By doing so, they can ensure that weaning occurs during summer months where temperate grasses are at their peak potential growth (Mallett and Cooke 1986). The gestation period is approximately 21 days, followed by 8-9 months within the pouch. Joeys are fully weaned between 10-12 months, however weight at this point has not been documented. Unlike other marsupials that undergo rapid growth within the pouch (McMahon et al. 2011; Werning 2013), common wombats experience a period of rapid growth where body size can double within 3-8 months post-weaning. Ontogeny is complete by approximately two years of age in prime conditions, or three years in field conditions (Wells 1989; Mcllroy 1973). In our modern sample, throughout the entire outer cortex, a band of parallel-fibered bone is observed, which can be associated with moderately fast bone deposition. On the inner cortices, woven bone, associated with faster growth, is observed above the inner circumferential lamellar layer, combined with sporadic Haversian remodelling. The occurrence of woven bone and parallel fibered bone, interrupted by Haversian remodelling may suggest periods of fast and moderate growth rates, and the need for localised bone renewal through deposition of secondary osteons (Amprino 1947; de Margerie et al. 2004). A hypothesis worth exploring is whether these transitions may correspond to the high post-weaning period of wombat growth (McIlroy 1973). We also observed bone growth marks in the modern sample, which are usually witnessed in all living vertebrates (Castanet et al. 1993; Woodward et al. 2013). 
Werning (2013) previously observed LAGs in $V$. ursinus indicating cyclical growth. These may have well been present in our modern sample but cannot be confidently ascertained due to the "erasing" effects of Haversian remodelling. Bone growth rates are also linked to metabolism and RMR (Padian et al. 2001; Cubo et al. 2008). Typically, animals with low metabolic rates reach adulthood after slow cyclical growth periods (which could be determined from LAGs or annuli). However, bone also requires oxygen for growth — as metabolism is a function of oxygen consumption (Huttenlocker et al. 2013; Cubo et al. 2008) - which is compromised within a burrow. In extreme cases, hypoxia (inadequate oxygen supply to tissue) can alter the function of a bone multicellular unit inhibiting osteoblast function (Marenzana and Arnett 2013). This is clearly not the case for wombats as evident through bone remodelling and extensive vascularity. We hypothesise that wombat bone develops quickly early in ontogeny, leading to a highly interconnected but disorganised vascular bone tissue, indicating that wombat bone modelling and remodelling is adapted to the burrow environment.

Both the fossil and modern specimens here have relatively similar vascular densities (MW = 11.47 vessels $/ \mathrm{mm}^{2}, \mathrm{FW}=11.09$ vessels $/ \mathrm{mm}^{2}$ ) suggesting that this trait may not have changed much across Vombatus through time. Vascularisation of the humerus in a North American, non-digging, Virginia opossum (Didelphis virginiana) was previously reported to be predominantly radial with very few longitudinal canals dispersed across largely parallelfibered bone matrix (Volkmann, 2017). While Virginia opossum bone vascularisation has not yet been quantified, its scarcity in Volkmann's (2017) sample is different from the relatively more complex vessel organisation in our modern wombat. This may hint at growth rate differences between digging and non-digging marsupials, even though the Virginia opossum, similarly to wombats, also shows a low metabolic rate (Walker and Berger, 1980). We note that the specimen examined by Volkmann (2017) was young and of unknown sex, so comparisons to wombats will benefit from including adult opossums in the future.

We acknowledge that our vascularity data will need verifying as they were difficult to collect in the fossil specimen, and only one sample in the modern and fossil categories were recorded. If future research supports significant differences between modern and Pleistocene wombats, these may be due to the availability of energy (Botha and Chinsamy 2000), with our data suggesting modern wombats experience larger energy inputs. Our fossil specimen dates to a period largely characterised by major temperature shifts, with a long-term trend towards progressively drier climates (Archer 1984, Kershaw et al. 2003). Common wombats may have 
only foraged on low quality fibrous foods. With the increasing grasslands as a by-product of agriculture post-European colonisation, the common wombat may have opportunistically shifted their diet to consume the higher energy-yielding grasses (Murray 1998). The greater vascular density in the modern wombat, as well as less dispersed osteocyte lacunae, may reflect a higher growth rate restricted by the same life history as the fossil specimen (Bromage et al., 2003).

\section{Conclusions}

This study provides pictorial and descriptive records of modern and fossil wombat humerus bone histology, showing that wombat forelimb microstructure may be adapted to biomechanical constraints and reflect burrow specific physiology. We hypothesise that due to development in the burrow, otherwise not conducive to bone growth, wombats evolved skeletal adaptations that allow for fast and strong bone building early in ontogeny, although this is based on only two samples and our observations could also be the result of atypical bone development. Unfortunately, the fossil specimen was heavily impacted by diagenesis. Nevertheless, our preliminary results encourage future research into intra-skeletal comparisons across ontogenetic assemblages of modern and fossil specimens to better understand temporal and spatial changes in wombat bone growth.

\section{Acknowledgements}

We would like to thank David McGregor (ANU) and Jambhika Godara (Olympus Australia) for technical assistance, Tim Denham and Elle Grono (ANU) for facilitating access to their equipment, the College of Arts and Social Sciences (ANU) and the Australian Research Council (ARC) for equipment funding; Mike Swinbourne (Adelaide) for inviting us to contribute our study to this special issue and hosting a stimulating "Wombat Through Time and Space" conference in 2018 in Adelaide. Palaeontological work at Baker's Swamp, and the survey of, and collection in, the Mt Fairy area were undertaken with permission from the relevant landowners. The interpretations presented in this study greatly benefited from discussions at the 2019 International Symposium on Palaeohistology in Cape Town, South Africa, where we held constructive conversations with Jennifer Botha-Brink, Anusuya Chinsamy, Lucas J. Legendre, and Germán Montoya-Sanhueza. Meg Walker received funding from the International Alliance of Research Universities (ANU-IARU). ARC funding supports 
Miszkiewicz (DE190100068) and Louys (FT160100450). We are thankful for feedback from the anonymous peer review and editors which improved our article.

\section{Conflict of interest statement}

The authors declare no conflicts of interest.

\section{Figure captions}

Fig. 1. The two wombat humerus specimens examined in this study. Top: caudal aspect of the fossil (a) and modern (b) specimen; bottom: cranial aspect of humerus of the fossil (c) and modern (d) specimen. Each specimen is shown so that the proximal end is at the top and the distal end is at the bottom of the bone.

Fig. 2. Overview of midshaft humerus bone histology in the modern wombat specimen, showing full cross-sections using three different types of light microscopy: a) - transmitted light, b) - linearly polarised light, c) - lambda cross-polarised light. Higher resolution images of each of the three scans are available from the supplementary files. MC - medullary cavity, DPC - deltopectoral crest protrusion.

Fig. 3. Bone histology features of the modern wombat midshaft humerus under lambda crosspolarised light. To the left of the image is a full cross-section (better quality version is shown in Fig. 2, and in the Supplementary file) indicating where each a) through to d) regions of interest were captured: a) - outer cortical bone region on the lateral aspect and b) lateral-caudal region showing parallel fibered bone (PFB); clustered and isolated secondary osteons (SO); and bone growth markers in the periosteal envelope in a); c) medial-caudal region of compact bone showing compact coarse cancellous bone (CCCB); d) lateral-caudal region showing outer cortical bone composed of parallel fibered bone (PFB) and isolated secondary osteons (SO) located well into the sub-periosteal envelope. Scale bar is $200 \mu \mathrm{m}$ in all images.

Fig. 4. Dispersal of osteocyte lacunae in the fossil (a, c, and middle segment of the cross-section to the left) and modern (b, d, and middle segment of the cross-section to the right) wombat midshaft bone. While largely impacted by diagenesis, osteocyte lacunae can still be identified in the fossilised bone with some lacunae appearing empty (black arrow in c). Osteocyte lacunae in the modern wombat bone are seen in much higher numbers and with well-defined borders that show canaliculi in some cases (white arrows in b and d). Scale bars are $50 \mu \mathrm{m}$ in a) and b), and $20 \mu \mathrm{m}$ in c) and d). 
Fig. 5. Bone histology features, mostly obscured by diagenetic damage, of the fossil wombat midshaft humerus under simple linear polarised light (a), where b) and c) indicate locations of bone magnified and shown under transmitted light: MC - medullary cavity; DPC deltopectoral crest protrusion; LV - primary longitudinal vascular canals seen along the outer medial-cranial cortical bone with osteocyte lacunae (OL) dispersed throughout the image; PFB: a possible thin parallel fibered bone on the sub-periosteal envelope observed on the medialcranial aspect of the thin section. Scale bar is $20 \mu \mathrm{m}$ in a) and $200 \mu \mathrm{m}$ in b).

\section{References}

Amprino, R. (1947). La structure du tissu osseux envisagée comme expression de différences dans la vitesse de l'accroissement. Archives de Biologie 58, 315-330.

Archer, M. (1984). The Australian marsupial radiation. In 'Vertebrate Zoogeography and Evolution in Australasia'. (Eds M. Archer and G. Clayton.) Pp. 661-886. (Hesperian Press, Carlisle).

Barboza, P.S. (1993). Digestive strategies of the wombats: Feed intake, fiber digestion, and digesta passage in two grazing marsupials with hindgut fermentation. Physiological Zoology 66, 983-999.

Barboza, P.S. and Hume, I.D. (1992a). Digestive tract morphology and digestion in the wombats (Marsupialia: Vombatidae). Journal of Comparative Physiology B 162, 552-560.

Barboza, P.S., and Hume, I.D. (1992b). Hindgut fermentation in the wombats: two marsupial grazers. Journal of Comparative Physiology B 162, 561-566.

Barboza, P.S., Hume, I.D., and Nolan, J.V. (1993). Nitrogen metabolism and requirements of nitrogen and energy in the wombats (Marsupialia: Vombatidae). Physiological Zoology 66, $807-828$.

Brewer, P., Archer, M., Hand, S., and Price, G.J. (2018). A new species of Miocene wombat (Marsupialia, Vombatiformes) from Riversleigh, Queensland, Australia, and implications for the evolutionary history of the Vombatidae. Palaeontologia Electronica 21.2.27A, 1-48. 
Boggs, D.F., Kilgore, D.L., and Birchard, G.F. (1984). Respiratory physiology of burrowing mammals and birds. Comparative Biochemistry and Physiology Part A: Physiology 77, 1-7.

Botha, J., and Chinsamy, A. (2000). Growth patterns deduced from the bone histology of cynodonts Diademodon and Cynognathus. Journal of Vertebrate Paleontology 20, 705-711.

Bromage, T.G., Goldman, H.M., McFarlin, S.C., Warshaw, J., Boyde, A., and Riggs, C.M. (2003). Circularly polarized light standards for investigations of collagen fiber orientation in bone. The Anatomical Record 274B, 157-168.

Bromage, T.G., Lacruz, R.S., Hogg, R., Goldman, H.M., McFarlin, S.C., Warshaw, J., Dirks, W., Perez-Ochoa, A., Smolyar, I., Enlow, D.H. and Boyde, A. (2009). Lamellar bone is an incremental tissue reconciling enamel rhythms, body size, and organismal life history. Calcified Tissue International 84, 388-404.

Castanet, J., Francillon-Vieillot, H., Meunier, F.J., and de Ricqlès, A. (1993). Bone and individual aging. In 'Bone Vol 7: Bone Growth - B'. (Ed B. K. Hall.) Pp. 245-283. (CRC Press, Boca Raton, Florida).

Chinsamy-Turan, A. (2012). 'Forerunners of Mammals: Radiation, Histology, Biology' (Indiana University Press, Bloomington).

Contreras, L.C., and McNab B.K. (1990). Thermoregulation and energetics in subterranean mammals. In 'Evolution of Subterranean Mammals at the Organismal and Molecular Levels' (Eds E. Nevo and O.A. Reig) Pp. 231-250. (Alan R. Liss, New York).

Cubo, J., Legendre, P., De Ricqlès, A., Montes, L., De Margerie, E., Castanet, J., and Desdevises, Y. (2008). Phylogenetic, functional, and structural components of variation in bone growth rate of amniotes. Evolution and Development 10, 217-227.

von den Driesch, A. (1976). A guide to the measurement of animal bones from archaeological sites. Peabody Museum of Archaeology and Ethnology 1, 1-137. 
Felder, A. A., Phillips, C., Cornish, H., Cooke, M., Hutchinson, J. R., and Doube, M. (2017). Secondary osteons scale allometrically in mammalian humerus and femur. Royal Society Open Science 4, 170431.

Francillon-Vieillot, H., de Buffrénil, V., Castanet, J. D., Géraudie, J., Meunier, F. J., Sire, J. Y., Zylberberg, L., and de Ricqlès, A. (1990). Microstructure and mineralization of vertebrate skeletal tissues. In 'Skeletal Biomineralization: Patterns, Processes and Evolutionary Trends' (Ed J.G. Carter) Pp 471-530 (Vol. 1. Van Nostrand Reinhold, New York).

Hedges, R. E., Millard, A. R., and Pike, A. W. G. (1995). Measurements and relationships of diagenetic alteration of bone from three archaeological sites. Journal of Archaeological Science 22, 201-209.

Hogg, R.T., Bromage, T.G., Goldman, H.M., Katris, J.A., Clement, J.G. (2017). The HaversHalberg oscillation and bone metabolism. In 'Building bones: bone formation and development in anthropology'. (Eds C.J. Percival and J.T. Richtsmeier) Pp. 254-280. (Cambridge University Press).

Huttenlocker, A.K., Woodward, H.N., and Hall, B.K. (2013). The Biology of Bone. In 'Bone histology of fossil tetrapods: advancing methods, analysis, and interpretation'. (Eds K. Padian and E-T. Lamm) Pp. 13-34 (University of California Press, Berkeley).

Johnson, C.N. (1998). The evolutionary ecology of wombats. In 'Wombats'. (Eds R.T. Wells, and P.A. Pridmore). Pp. 34-41. (Royal Zoological Society of South Australia, Surrey Beatty and Sons in association with the Royal Zoological Society of South Australia, Norton, N.S.W).

Kendall, C., Eriksen, A. M. H., Kontopoulos, I., Collins, M. J., and Turner-Walker, G. (2018). Diagenesis of archaeological bone and tooth. Palaeogeography, Palaeoclimatology, Palaeoecology 491, 21-37.

Kershaw, P., Moss, P., and Van Der Kaars, S. (2003). Causes and consequences of long-term climatic variability on the Australian continent. Freshwater Biology 48, 1274-1283. 
Lee, A.H., Huttenlocker, A.K., Padian, K., and Woodward, H.N. (2013). Analysis of growth rates. In 'Bone Histology of Fossil Tetrapods: Advancing Methods, Analysis, and Interpretation'. (Eds K. Padian and E-T. Lamm) Pp. 217-252. (University of California Press, Berkeley).

Lee, T. C., Staines, A., and Taylor, D. (2002). Bone adaptation to load: microdamage as a stimulus for bone remodelling. Journal of Anatomy 201, 437-446.

Legendre, L. J., and Botha-Brink, J. (2018). Digging the compromise: investigating the link between limb bone histology and fossoriality in the aardvark (Orycteropus afer). PeerJ 6, e5216.

Louys, J. (2015). Wombats (Vombatidae: Marsupialia) from the Pliocene Chinchilla Sand, southeast Queensland, Australia. Alcheringa: An Australasian Journal of Palaeontology 39, 394-406.

Mallett, K., and Cooke, B. D. (1986). The ecology of the common wombat in South Australia. Nature Conservation Society of South Australia, Adelaide.

Marenzana, M., and Arnett, T. R. (2013). The key role of the blood supply to bone. Bone Research 1, 203.

de Margerie, E. D., Robin, J. P., Verrier, D., Cubo, J., Groscolas, R., and Castanet, J. (2004). Assessing a relationship between bone microstructure and growth rate: a fluorescent labelling study in the king penguin chick (Aptenodytes patagonicus). Journal of Experimental Biology 207, 869-879.

Marín-Moratalla, N., Jordana, X., and Köhler, M. (2013). Bone histology as an approach to providing data on certain key life history traits in mammals: implications for conservation biology. Mammalian Biology 78, 422-429.

McNab, B. K. (1979). The influence of body size on the energetics and distribution of fossorial and burrowing mammals. Ecology 60, 1010-1021. 
McIlroy, J.C. (1973). Aspects of the ecology of the common wombat Vombatus ursinus (Shaw, 1800). PhD. Thesis, Australian National University, Canberra.

McMahon, C. R., Buscot, M. J., Wiggins, N. L., Collier, N., Maindonald, J. H., McCallum, H. I., and Bowman, D. M. (2011). A two-phase model for smoothly joining disparate growth phases in the macropodid Thylogale billardierii. PloS One 6, e24934.

Miszkiewicz, J.J., Louys, J., O’Connor, S. (2019). Microanatomical record of cortical bone remodeling and high vascularity in a fossil giant rat midshaft femur. The Anatomical Record 302, 1934-1940.

Miszkiewicz, J.J., Louys, J., Beck, R.M.D., Mahoney, P., Aplin, K., O’Connor, S. (2020). Island rule and bone metabolism in fossil murines from Timor. Biological Journal of the Linnean Society 129, 570-586.

Noonan, M. J., Newman, C., Buesching, C. D., Macdonald, D. W. (2015). Evolution and function of fossoriality in the Carnivora: implications for group-living. Frontiers in Ecology and Evolution 3, 116.

Montoya-Sanhueza, G., and Chinsamy, A. (2017). Long bone histology of the subterranean rodent Bathyergus suillus (Bathyergidae): ontogenetic pattern of cortical bone thickening. Journal of Anatomy 230, 203-233.

Murray, P.F. (1998). Palaeontology and palaeobiology of wombats. In 'Wombats'. (Eds R.T. Wells and P.A. Pridmore) Pp. 1-33. (Royal Zoological Society of South Australia, Surrey Beatty and Sons in association with the Royal Zoological Society of South Australia, Norton, N.S.W).

Padian, K., and Lamm, E-T. (2013). 'Bone Histology of Fossil Tetrapods: Advancing Methods, Analysis, and Interpretation.' (University of California Press).

Padian, K., de Ricqlès, A. J., and Horner, J. R. (2001). Dinosaurian growth rates and bird origins. Nature 412, 405. 
de Ricqlès, A. J. (2011). Vertebrate palaeohistology: Past and future. Comptes Rendus Palevol 10, 509-515.

Robling, A. G., Castillo, A. B., and Turner, C. H. (2006). Biomechanical and molecular regulation of bone remodeling. Annual Review of Biomedical Engineering 8, 455-498.

Scott, G. G., and Richardson, K. C. (1987). Appendicular osteological differences between Lasioruinus latifrons (Owen, 1845) and Vombatus ursinus (Shaw, 1800) (Marsupialia: Vombatidae). Records of the South Australian Museum 22, 95-102.

Shapiro, F., and Wu, J. Y. (2019). Woven bone overview: structural classification based on its integral role in developmental, repair and pathological bone formation throughout vertebrate groups. European Cells \& Materials 38, 137.

Singer, B.S. (2014). A Quaternary geomagnetic instability time scale. Quaternary Geochronology 21, 29-52.

Slon, V., Stein, D., Cohen, H., Medlej, B., Peled, N., and Hershkovitz, I. (2014). Hyperostotic bone disease in a wombat (Vombatus ursinus). Research in Veterinary Science 97, 88-95.

Straehl, F. R., Scheyer, T. M., Forasiepi, A. M., MacPhee, R. D., and Sánchez-Villagra, M. R. (2013). Evolutionary patterns of bone histology and bone compactness in xenarthran mammal long bones. PLoS One 8, e69275.

Vleck, D. (1979). The energy cost of burrowing by the pocket gopher Thomomys bottae. Physiological Zoology 52, 122-136.

Volkmann, G. (2017). Comparative osteohistological analysis of two mesopredators Didelphis virginiana and Procyon lotor. MSc Thesis, Oklahoma State University, Stillwater.

Walker, J. M., and Berger, R. J. (1980). The ontogenesis of sleep states, thermogenesis, and thermoregulation in the Virginia opossum. Developmental Psychobiology 13, 443-454. 
Warburton, N. M., Grégoire, L., Jacques, S., and Flandrin, C. (2014). Adaptations for digging in the forelimb muscle anatomy of the southern brown bandicoot (Isoodon obesulus) and bilby (Macrotis lagotis). Australian Journal of Zoology 61, 402-419.

Warshaw, J., Bromage, T. G., Terranova, C. J., and Enlow, D. H. (2017). Collagen fiber orientation in primate long bones. The Anatomical Record 300, 1189-1207.

Wells, R. T. (1973). Physiological and behavioural adaptions of the hairy-nosed wombat (Lasiorhinus latifrons Owen) to its arid environment. PhD Thesis, University of Adelaide, Adelaide.

Wells, R. T. (1978). Thermoregulation and activity rhythms in the hairly-nosed wombats, Laisorhinus latifrons (Owen),(Vombatidae). Australian Journal of Zoology 26, 639-651.

Wells, R. T. (1989). Vombatidae. In 'Fauna of Australia. Vol 1B. Mammalia'. (Eds B.J. Richardson and D. Walton.) Pp. 755-768. (Australian Government Publishing Services, Canberra).

Werning, S. A. (2013). Evolution of bone histological characters in amniotes, and the implications for the evolution of growth and metabolism. PhD Thesis, University of California, Berkeley.

Withers, P. C. (1972). Physiological adaptations of the Hairy-nosed Wombat, Lasiorhinus latifrons, to its fossorial habit. BSc (Hons) Thesis, University of Adelaide, Adelaide.

Woodward, H.N., Padian, K., and Lee, H. (2013) Skeletochronology. In 'Bone histology of fossil tetrapods: advancing methods, analysis, and interpretation' (Eds K. Padian and E-T. Lamm) Pp. 195-215. (University of California Press, Berkeley).

Woolnough, A. P., and Steele, V. R. (2001). The palaeoecology of the Vombatidae: did giant wombats burrow?. Mammal Review 31, 33-45. 